\title{
Analysis and Redesign of Simon Mazorodze and Chitungwiza Road Intersection in Harare, Zimbabwe
}

\author{
Tinashe Philip ${ }^{1}$, Samson Shumba ${ }^{2}$, Liliana D. Vassileva ${ }^{3}$ and Namatirai Cheure ${ }^{4}$ \\ \{tinashephilip20@gmail.com ${ }^{1}$, sshumba08@gmail.com², vassileva@eng.uz.ac.zw ${ }^{3}$ \} \\ Department of Civil Engineering, University of Zimbabwe, P.O Box MP167 Mount Pleasant, \\ Harare, Zimbabwe
}

\begin{abstract}
This project focused on analyzing and redesigning of Simon Mazorodze/Chitungwiza road intersection in Harare, Zimbabwe. Different types of intersections and the cost effective ways of improving roundabout intersections were analyzed using standard procedure. A 96 hour manual traffic survey was conducted at the intersection to determine the current traffic volumes and current capacity of the intersection and then determination of the current intersection performance. Microsoft office, Spreadsheets and AutoCAD were used for design analysis. The results showed that the intersection was not able to handle the high traffic volumes passing through it, hence the justification of upgrading the current intersection. The most appropriate design was chosen, which is designing of a roundabout with bypass slip lanes according to American Standards. The study concluded that the proposed design is able to cope with the traffic for a design life of 20 years. An overpass is recommended to cater for pedestrians.
\end{abstract}

Keywords: Intersection, Roundabouts, Highways, Traffic Volumes, Congestion, Bypass, Slip-lanes.

\section{Introduction}

\subsection{Background}

Zimbabwe has a comprehensive road network linking different parts of the country and providing access to neighboring countries for imports and exports .The country is experiencing an increase in motorization while roads have deteriorated resulting in high road accidents .According to World Health Organization in 2011, the estimated road traffic death rate is 3669 people per year with road traffic injuries costing about $2 \%$ of the gross domestic product (GDP) in the country .If no mitigation is done projections shows that situation will get worse with road accidents forecasted to rise because of increase in motorization from the ninth to the second leading cause of disabilities .Road safety should therefore take the first priority in transport systems . Most intersections in Zimbabwe particularly Harare are not performing efficiently under heavy congestion not only because of increasing motorization but also because these intersections have exceeded their design life .Intersections have to be upgraded according to the traffic increase in order to maintain highest level of safety and a better level of service .This project mainly focused on upgrading of Simon Mazorodze and

ACRID 2017, June 20-21, Victoria Falls, Zimbabwe

Copyright $(2017$

DOI 10.4108/eai.20-6-2017.2270747 
Chitungwiza road intersection because of the attention it requires as it links not only Harare with other parts of the country but also Zimbabwe with other trading partners throughout Africa.

\subsection{Problem Statement}

The capacity of the intersection at Simon Mazorodze and Chitungwiza road have been exceeded due to increase in traffic volumes passing through this intersection resulting in poor performance of the intersection especially during peak hours hence the proposal of redesign of the intersection.

\subsection{Project Justification}

The intersection is very vital to the economy of Zimbabwe as Simon Mazorodze road (regional corridor road) is the major route and gateway of the country to its major trading partners like South Africa, Mozambique, D.R.C and Zambia. The intersection also links Harare with other parts of the country, local residential areas and industrial areas like Boka Tobacco Sales Floors. Therefore priority should be given to this route in order to reduce travelling costs and improve services so as to increase the competitiveness of the country's exports, reduce delivery costs of imports, delays and uncertainties in trade routes, develop adequate national network, open the way for export expansions and improve the safety of road transport and security of people along the corridor.

\subsection{Research Objectives}

\subsubsection{Main Objective}

To analyze and redesign Simon Mazorodze and Chitungwiza Road intersection according to the specified standards to ensure safety to motorists and pedestrians.

\subsubsection{Specific Objectives}

I. To investigate the perfomance or adequacy of the current intersection.

II. To study possible methods of improving the current intersection and evaluate each method.

III. To redesign the intersection to cater for the increased traffic using the appropriate standards.

\section{Intersections}

\subsection{Classification}

An intersection is defined as the general area where two or more highways join or cross, including the roadway and roadside facilities for traffic movements within the area .Intersections are an important part of a highway facility because to a greater extent, the efficiency, safety, speed, cost of operation and capacity of the facility depend on their design. Most commonly intersections are classified according to geometric configuration, traffic control mechanism and number of conflicts [1].The type of intersection control that has to be used depends on the traffic volume, road geometry, cost involved, importance of the road etc. 
[7].Roundabouts are an example of rotary intersections which have considerable safety advantages over other types of at grade intersections [2].

\subsection{Level of Service}

The level of service, (LOS), is a qualitative measure that represents and/or defines the operational conditions in a traffic stream as related to the facility and the perception of these conditions by the vehicle drivers and the passengers, [6] .Five levels of quality (LOS) have been developed for traffic between free-flow and the capacity conditions and a letter is assigned for each level. A for near free-flow conditions and $\mathbf{E}$ for near-capacity conditions .A single level $\mathbf{F}$ was reserved for congested and unstable traffic [8]. The LOS of an intersections is determined by measuring average delays at the intersection and the level of service is generally improved by adding lanes if space and funds are available, improving the lateral clearance, changing the route of heavy vehicle [10].

\subsection{Roundabouts}

\subsubsection{Types of Roundabouts}

A roundabout is a channelized intersection with one-way traffic flow circulating around a central island that is usually kerbed [10]. All traffic, through as well as turning traffic enters this one-way flow. Priority is given to the traffic already in the circle .Entries on a roundabout are controlled by 'Give Way signs and markings .The principle objective of the roundabout design is to ensure safe interchange of intersecting traffic streams efficiently with very minimum delay .Designing the geometry of a roundabout involves choosing the best operational and capacity performance while retaining the best safety enhancements [1]. Generally there are three main types of roundabouts, normal, mini and double roundabouts. Other forms of roundabouts which are variants of these types including ring Junctions, grade separated roundabouts and signalized roundabouts.

\subsubsection{Roundabout Capacity}

According to [4] the level of service of a roundabout is determined by how its traffic volumes compare with its processing capacity .Apart from other parameters according to an informational guide the entry width is the largest determinant of a roundabout's capacity [5]. The capacity of an approach is not dependent merely on the number of entering lanes, but on the total width of the entry, thus the entry width increases the entry capacity .In order to maintain highest level of safety, the design should provide the minimum width necessary for capacity and accommodation of the design vehicle.

\subsubsection{Improving Roundabouts}

The following design solutions can be employed to improve the flow of traffic at roundabouts:

1. Addition of slip lanes adjacent to the roundabout: (in four-leg roundabouts only for leftturn movements); This caters for heavy left turning traffic resulting in less traffic passing through the intersection. The entry lane and the slip lane are separated by a raised island. 
According to [3] two common types of left-turn bypass lanes are used at single-lane and multilane roundabouts:

i. Where bypass traffic yields to conflicting exiting vehicles (sometimes referred to as a partial bypass lane), there is high entry angle left turn lane

ii. Where the bypass lane joins the intersecting roadway as an additional lane or in a downstream merging operation. [3]

2. Turn the roundabout into a three-lane or multilane version and dualisation of all approach legs: where possible for an example $1 \mathrm{~km}$ section. The capacity of the intersection is increased in that more traffic is processed at the same time and two or more heavy trucks can circulate at the intersection same time but however studies including [4] shows that this reduces safety, and sometimes lead to poor use of the inner lane.

\section{Use of bypass roads}

This involves the use of other alternative routes instead of the one available, thus some traffic would bypass the intersection increasing the capacity of the intersection. [10]

\section{Flaring (Tapering) of the Entries}

Flaring of the entries over a short tapering distance from entry has been reviewed by studies to increase the capacity by about 20 percent [5]. However other studies by [11] showed that increasing entry width increases accidents rates between entering and circulating vehicles .Entry widths should therefore be minimized and flare lengths maximized to achieve the desired capacity with minimal effect on crashes [4].

\section{Grade Separation}

The greatest efficiency, safety, and capacity are attained when the intersecting traveled ways are at different grades [1]. Construction of this intersection is however expensive and requires a lot of space which might not be readily available at the intersection.

\section{Entry Metering}

During peak periods, flow from one entry can dominate downstream entries to the point that insufficient acceptable gaps are available causing excessive delays and queues at the downstream entry. Entry metering becomes necessary at such points and is usually done by installing a traffic control signals to meter the flow as it approaches the roundabout. A basic metering system consist of two components first one consist of a queue detector on the downstream entry that is experiencing excessive delays and queues. This detector is placed relatively far back on the downstream entry to detect when there is long queue that has formed due to congestion. When a long queue is detected, the signal controller activates the metering signal. The second one consist of a metering signal on the dominant approach, preferably set far enough back from the entry to minimize confusion with the yield sign .Another method of metering is the use with appropriate timing of nearby upstream signalized intersection on the subject approach road. Unlike pure entry metering, such controls may stop vehicles from entering and leaving the roundabout .Expected queue lengths on the roundabout exits between the metering signal and the circulatory roadway should be compared with the proposed queuing space .However because of additional objectives and constraints, metering by upstream signals is generally not as effective as direct entrance metering and more than one entrance can be metered .Entry metering may generally result in bunching of traffic and 
introducing more of the longer duration gaps and it is also affected by power shortages. Figure 1 shows an example of entry metering on roundabouts.

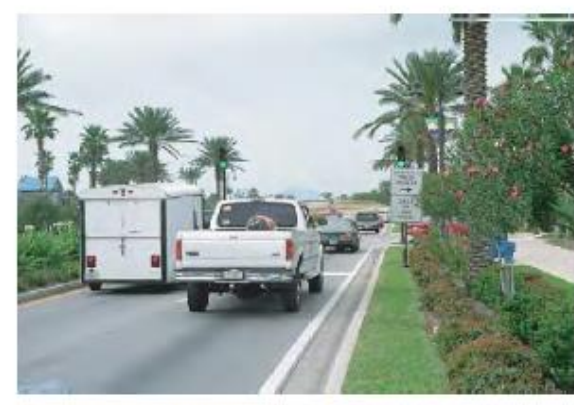

(a) Approach metering signal Clearwater, Florida

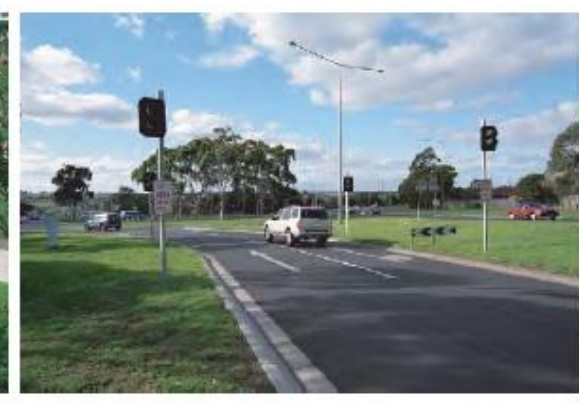

(b) Approach metering signal Melbourne, Victoria, Australia

Fig. 1. Entry metering on roundabouts [4]

\section{Footbridges}

At roundabouts where there are many pedestrians users, introduction of a footbridge helps in controlling interrupting by pedestrians to traffic flow on roundabout .Footbridges together guardrail helps in channeling pedestrians in one single file and cross the roundabout without traffic flow interruption.

\section{Methodology}

\subsection{Study Area}

The study area is located at $17^{\circ} 55^{\prime} 13^{\prime \prime}$ South and $30^{\circ} 59^{\prime} 06$ "East. The intersection is about $15 \mathrm{~km}$ from the Central Business District of Harare in Zimbabwe. A roundabout was constructed at this intersection about 20 years ago .It is a two lane kerbed roundabout with two way entry and exit on each approach .Simon Mazorodze was dualised in 2011 whist Chitungwiza Rd and High Glen Rd are two way single lane roads. Simon Mazorodze (North) crosses a small bridge less $10 \mathrm{~m}$ from intersection whilst High Glen Road crosses Mukuvisi River less than $100 \mathrm{~m}$ from the intersection. Figure 2 show the aerial view of the intersection. 


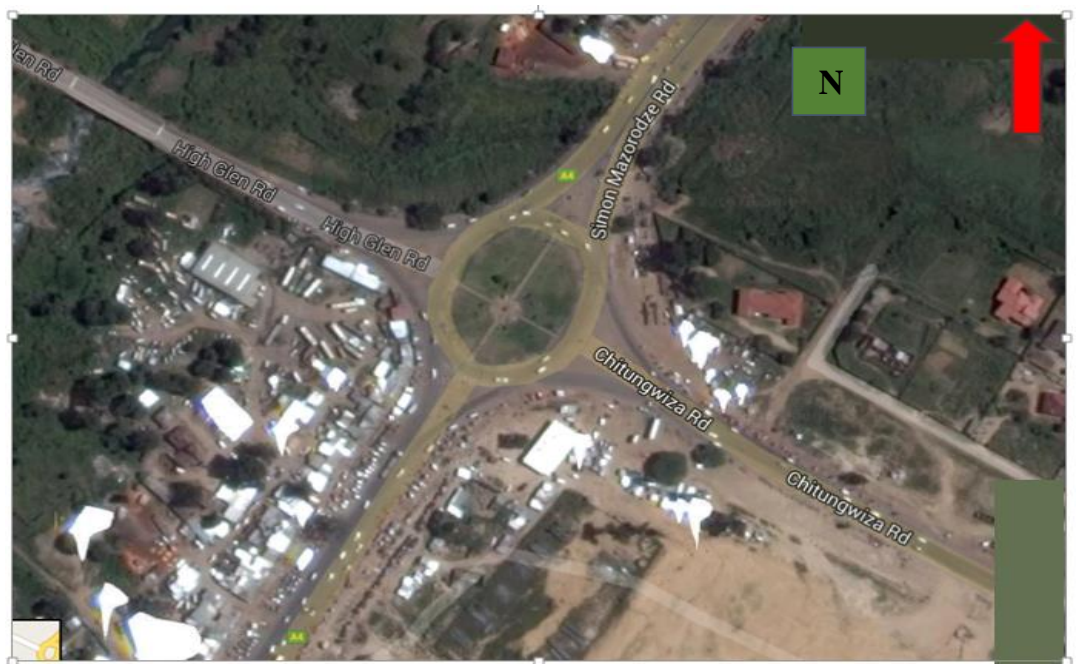

Fig. 2. Aerial view of the intersection from Google earth imagery

\subsection{Traffic Data Collection}

Traffic movement on a roundabout is quite complex, for this project, only approaching traffic and left turning traffic was counted and all other movements were estimated based on peak hour observations. Ideally it is recommended that traffic counts should be done using video cameras but this method is expensive and requires high quality cameras. Manual traffic counts were conducted during peak hour periods from Monday 15 February 2016 to Thursday 18 February 2016. The traffic was the converted to passenger car unit equivalence using the factors provided by City of Harare. The peak period was from 0630 to $0730 \mathrm{hrs}$ in the morning, from 1230 to $1330 \mathrm{hrs}$ in the afternoon and from 1700 to 1800 hours in the evening.

\subsection{Site Survey}

\subsubsection{Land Use and General Observations}

There is extensive vending within and around the intersection. No control exist on pick and drops is being implemented and this is affecting the operation of the intersection especially during the peak hours. It was also observed during peak hours that when long queues (more than $100 \mathrm{~m}$ ) are formed, drivers become impatient and break the intersection rules and enter into the weaving zone resulting in more traffic in circulation creating less gaps for yielding traffic to enter. Accumulation of traffic also started when a large number of heavy vehicles consecutively enter into the weaving zone. Figure 3 shows some of the illegal activities taking place at the intersection. 


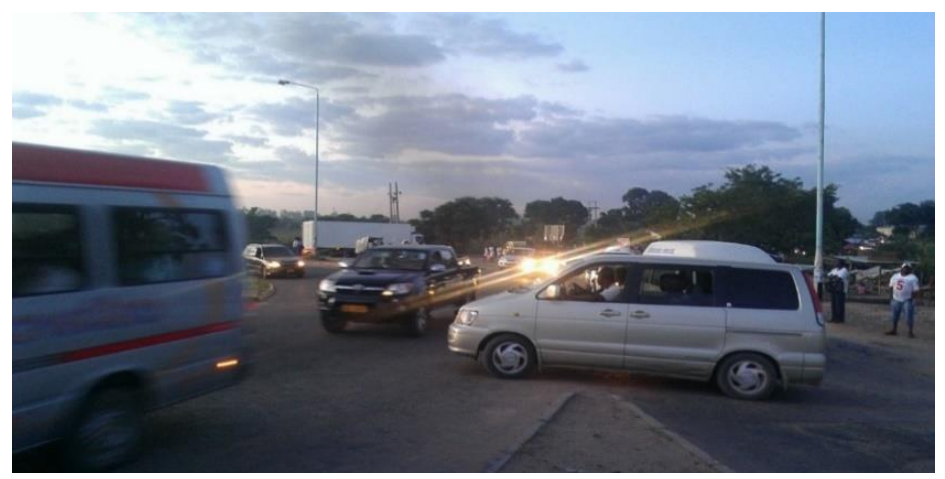

Fig. 3. Evening peak hour congestion at Simon Mazorodze/Chitungwiza Intersection (16/02/2016)

\section{$4 \quad$ Results and Discussions}

\subsection{Analysis of Traffic Count Results}

Traffic counts were conducted on 15 minutes interval by the author and only the approaching and left turning traffic was counted right turning and straight traffic was estimated from the observation made at the intersection. The average delays for each approach were recorded for the different peak periods. The delays for light vehicles were taken as the time between the arrival of a vehicle at the roundabout to the time the driver finds an acceptable gap to enter into the roundabout. The minimum for each approach was ten minutes and the maximum was thirty minutes, hence the formation of long queues on each approach .Figure 4 and 5 below shows the results of traffic flow during the morning peak hour.

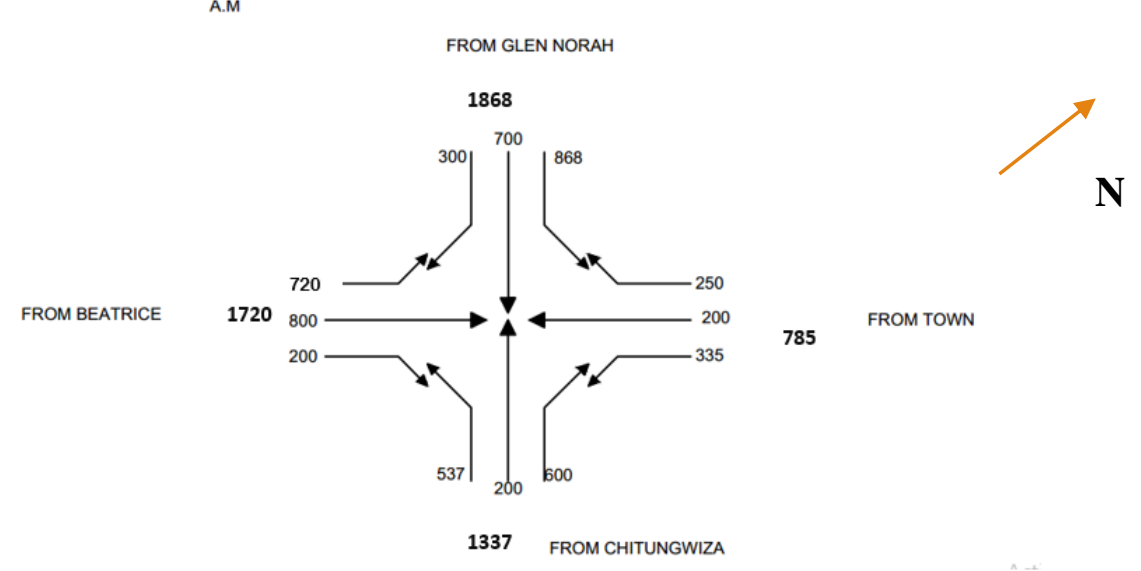

Fig. 4. Traffic flow during the morning peak hour in $\mathrm{pcu} / \mathrm{hr}$

Traffic movement at the current intersection during the evening peak hour are shown in Figure 5. 


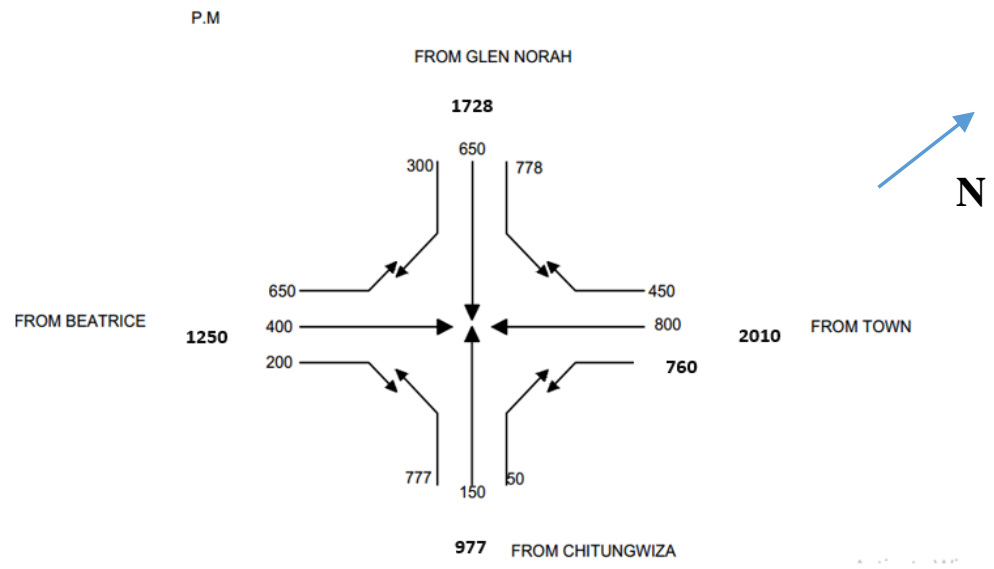

Fig. 5: Traffic flow during the evening peak hour in $\mathrm{pcu} / \mathrm{hr}$

Variation of traffic composition for the morning peak hour is shown in the Figure 6.

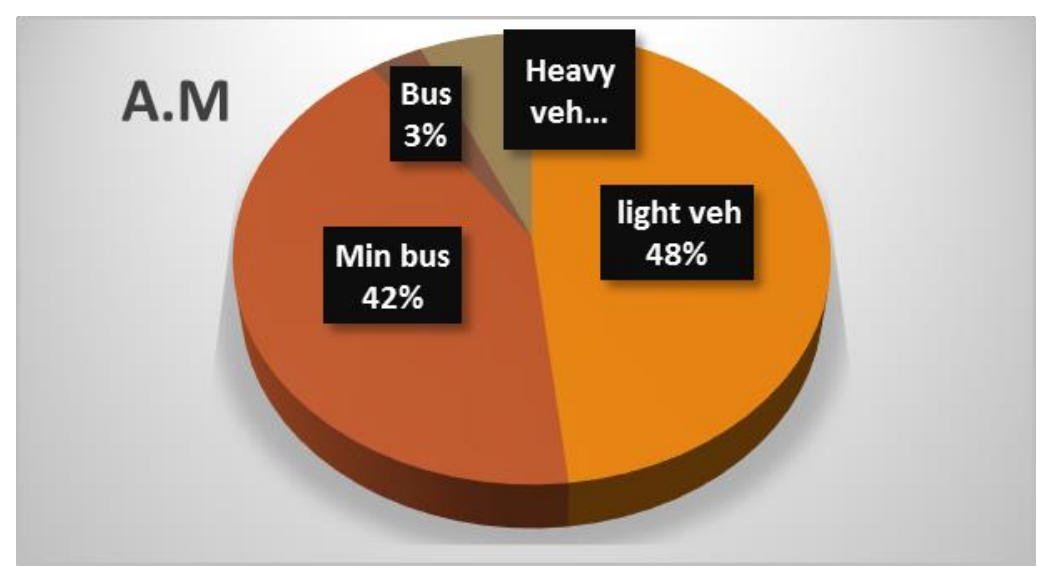

Fig. 6. Traffic composition during the morning peak hour.

The actual turning movements for maximum flows are shown in Figure 7. 


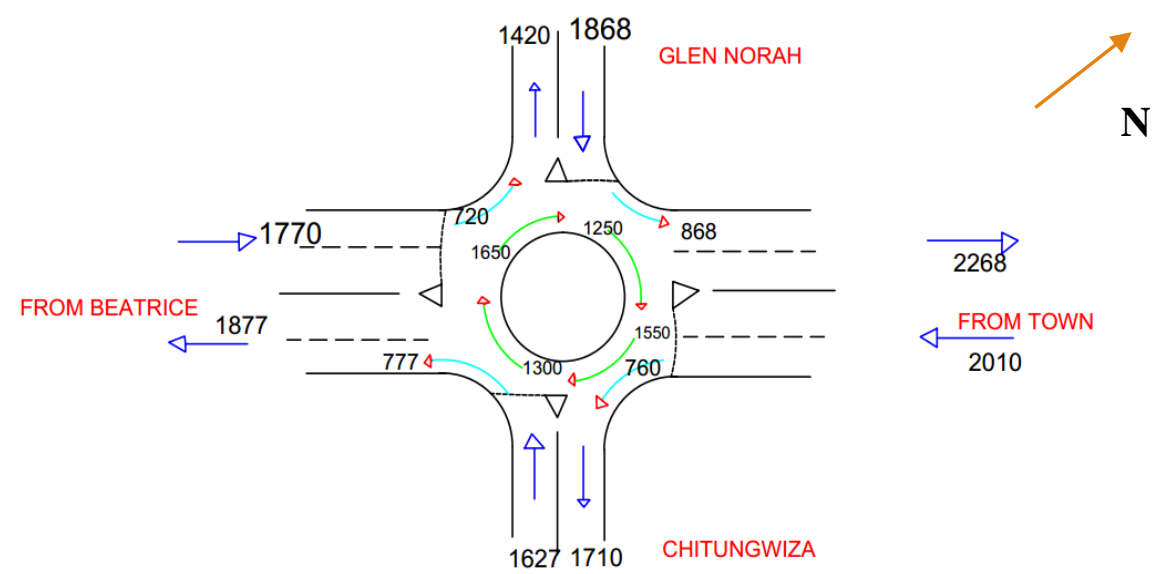

Fig. 7. Actual turning movements for the maximum flows.

\subsection{Peak Hour Factor}

The maximum mean traffic count which was recorded from Simon Mazorodze (from South) which is $1868 \mathrm{pcu} / \mathrm{hr} / \mathrm{lane}$ was used to calculate the peak hour factor .Assuming an equal distribution of traffic for the four approaches to get the critical condition of the intersection which was then used to assess the performance of the intersection. The calculated peak hour factor $\left(\mathrm{phf}_{15}\right)$ was 0.92 and the service flow was $2030 \mathrm{pcu} / \mathrm{hr} / \mathrm{lane}$, headway $\left(\mathrm{h}_{\mathrm{t}}\right)$ is 1.93 seconds and the headway distribution (out the probability of gaps which are greater than or equal to an acceptable time, (taken as 6 seconds)) was $4.42 \%$ during the morning peak hour .The level of Service was determined to fall between $\mathrm{D}$ and $\mathrm{E}$ with a maximum service flow of $2396 \mathrm{pcu} / \mathrm{km} / \mathrm{lane}$.Volume to capacity ratio was obtained as 1.198 it was concluded that the level of service during the morning peak hour was level F. This was consistent with the results obtained using the measured delays per vehicle.

\subsection{Historical Traffic Data}

No historical traffic counts were retrieved from the City of Harare for any of this intersection approaches .For design purposes a traffic growth rate of $5 \%$ is assumed.

\section{Design Work}

The criterion of the design is based on the calculations from the analysis of the results in the previous section. For this project a growth rate of $4 \%$ will be employed for the design periods of 10 and 20 years. The analysis considers both existing and future traffic. Design reference flows before projection are the maximum flows at the current intersection. Presented below are design alternatives to improve the traffic flow efficiency at the current intersection.

Turn the roundabout into a three-lane or multilane version and dualise the High Glen and Chitungwiza Road 
The road dualisation would be done for an example $1 \mathrm{~km}$ section from the roundabout. This increases the capacity of the approaches and hence capacity of the roundabout. Ultimately there would be better traffic flow efficiency and reduced congestion at the intersection but however studies on multilane roundabouts shows that safety is reduced and there is overall promotion of side crashing of vehicles due to poor use of the inner lane .There is also no enough land for dualisation of High Glen Rd and Chitungwiza Rd therefore this solution cannot be implemented at the current location.

Use of bypass roads

This involves identifying bypass roads and widening them so that they can accommodate heavy vehicles. All left turning traffic would bypass the intersection by making use of these bypass roads. Figure 8 shows the bypass road at the current intersection.

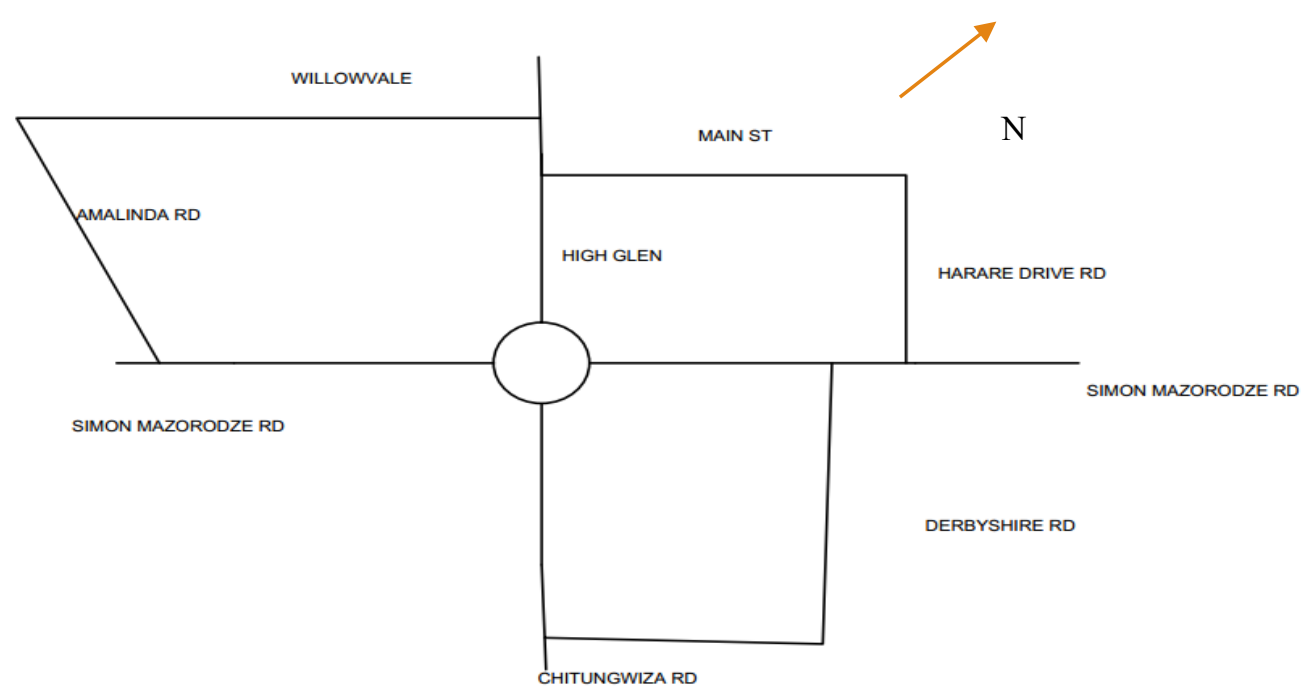

Fig. 8. Bypass roads at the current intersection

Use of bypasses reduces the number of conflicting traffic which then makes the roundabout more efficient and safe but however the bypass roads available are too far away from the intersection as shown in Figure 8 and therefore drivers' travel distance would increase and this is does not attract many road users since more fuel is used .Hence this solution is not feasible at the current location.

\section{Grade Separation}

Grade separation of some conflicting traffic movement increase the performance of the intersection and substantially the capacity is increased and the delays and accident potentials are reduced. Construction of this kind of intersection is however expensive and requires a lot of space which is not readily available at the intersection, therefore this is solution is also not feasible at the current location.

Redesigning of roundabout

Figure 9 shows the proposed solution. 


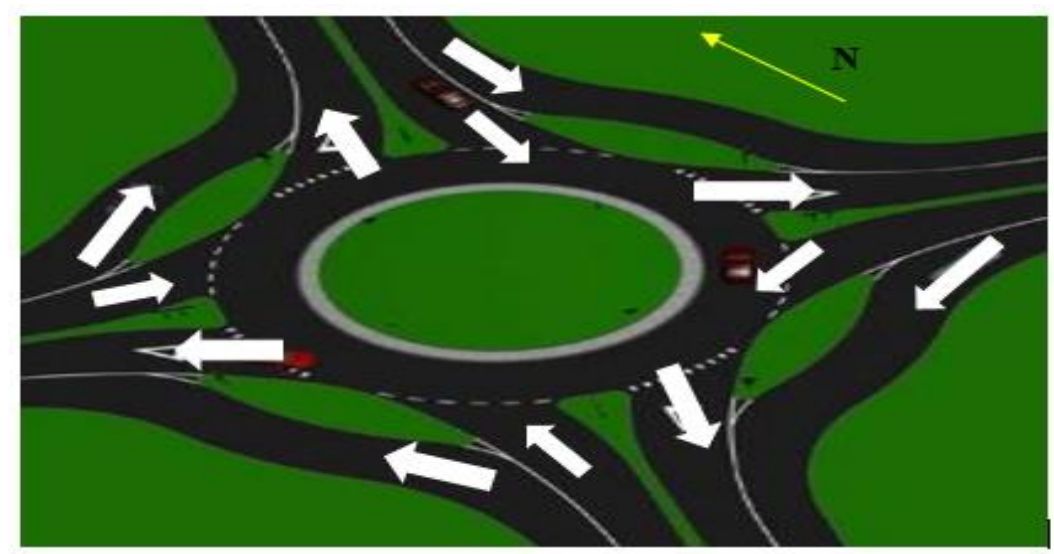

Fig. 9. Roundabout with slip lanes

This redesign would involve the following processes:

1. Adding bypass slip lanes adjacent to the roundabout to all approaches;

2. Widening of the entry and exit width

The current entry width is $7.5 \mathrm{~m}$ and the proposed width is $12.0 \mathrm{~m}$, the current exit width is $5.5 \mathrm{~m}$ and the proposed width is $10 \mathrm{~m}$. This increase results in better accommodation of large trucks resulting in less delays at the current intersection.

3. Reducing the size of the inscribed circle and widening of the circulation lanes.

The current inscribed circle is egg-shaped with a longest diameter of $78.0 \mathrm{~m}$ and this will be reduced to $76.0 \mathrm{~m}$. This is large enough to accommodate design vehicle and maintain required deflection and increasing the capacity as well.

4. Introduction of steel guardrail along Simon Mazorodze Splitter Island

5. Construction of a retaining wall on the steep slope between Simon Mazorodze (To Town) and High Glen approach before introduction of a slip lane.

The proposed geometric parameters from Australian and American standards were used to check whether the capacities are sufficient for the design traffic even after ten years. Equation (1) was used to check the reserve capacities and this was derived from [9] and [11].

$$
\text { Reserve capacity }=(\text { entry capacity-entry flow }) / \text { entry flow } * 100 \%
$$

After computing the calculation it was deduced that all approaches of the current intersection had negative reserve capacities meaning that the roundabout is currently not able to cater for the entry flow .Capacity of the weaving sections was further computed after removing all the left turning traffic and all the reserve capacities changed to positive meaning the new design increases the entry capacities. The reserve capacities also remained positive after a ten years assuming a 4\% traffic growth rate. It can therefore be concluded that the proposed design with bypass lanes would sufficiently improve the intersection.

\section{Advantages of the proposed design}

With this design, all left turning traffic would bypass the intersection resulting in less conflicting vehicles, widening the entry, exit and circulatory width would increase the 
capacity of the intersection and hence less conflicts as well .Introduction of guardrail increases the safety of pedestrians. Therefore entirely redesigning of the roundabout would not only result in high performance of the roundabout but also increase in safety of road users. All road construction would make use of locally supplied material thus gravel from Dzivaresekwa or Warren Park in Harare and the steel guardrail would be supplied by local suppliers in Harare making the construction work cheaper.

\section{Disadvantages of the design}

Even though the proposed design is cost effective the cost of construction is generally expensive since it also includes construction of diversion routes which is used by the traffic whilst the intersection is under construction.

\subsection{Bill of Quantities}

The total cost from the bill of quantities for the project summed to USD 170000 .

\section{Conclusions and Recommendations}

\subsection{Conclusions}

The proposed intersection design, (roundabout with slip-lanes) is adequate for the given location and the design flows corresponding to the Simon Mazorodze/Chitungwiza Intersection. The proposed design provides a good balance of capacity, delays and good visibility whilst at the same time, ensuring drivers comfort and increased safety to all road users, and this is achieved through separation of conflicting traffic through the use of bypass slip lanes. From the capacity checks carried out, the proposed roundabout design is able to cope with the present traffic volumes as well as the design volumes (at most 20 years). This design is also cost effective since most of the materials required for construction are locally available and also it makes use of the available land.

\subsection{Recommendations}

For maximum performance of the proposed design the following design considerations are recommended:

1. Due to increased numbers of pedestrians crossing the Simon Mazorodze (To Beatrice) due to rise in business operations in the vicinity of the intersection, an overpass (footbridge) is recommended to be constructed over south side of Simon Mazorodze to support the guardrail in the proposed design. This would restrict pedestrians to cross only at the designated point hence increasing the safety of pedestrians.

2. Construction of raised islands (with mountable kerbs) is recommended in between the approach legs and the slip lanes. Between Simon Mazorodze (To Town) and High Glen, there is a steep slope, therefore construction of a retaining wall is recommended before the construction of slip lanes.

3. An overpass would a more effective way to reduce congestion at this intersection with Simon Mazorodze road under High Glen road. This alternative does not only improve the capacity and efficiency of the intersection, but it also improves the safety of road users and the aesthetics of the intersection. 
4. Construction of long distance bus rank in the vicinity of the intersection which will cater for long distances buses, taxis and mini buses. This would eliminate all the interruption in traffic movement at the intersection and also restore good visibility to road users and all vendors to be put within this rank.

\section{References}

[1] American Association of State Highway and Transportation Officials (AASHTO).: A Policy on Geometric Design of Highways and Streets, Washington, D.C (2011)

[2] South African National Road Agency (SANRAL).: South African Geometric Design Guidelines (2003)

[3] Ausroads.: Guide to Traffic Engineering Practice, Part 4B-Roundabouts (2011)

[4] Morris, M., Neil, J.R. and Pederson, E.: NCHRP Report 672-Roundabouts Information Guide (2010)

[5] Federal Highway Administration.: An informational Guide for Roundabout Geometric Design, pp. 127-181 (2013)

[6] Norwalk.: Intersection Design-Transportation Management and Planning, pp. 73 (2012)

[7] Tom, V. and Mathew, K.: Traffic Intersections-Introduction to Transportation Engineering, pp. 17. Available at : http://nptel.ac.in/courses/105101087/downloads/Lec. 39.pdf (2007)

[8] Che, W.F.: The Civil Engineering Handbook, West Lafayette, Indiana, CRC Press (1995)

[9] O’Flaherty, C.A.: Transport Planning and Traffic Engineering, Elsevier, Oxford (1997)

[10] Vassileva, L.D.: Highway Design, Transportation Systems and Infrastructure, University of Zimbabwe, Harare (2015)

[11] Salter, R.J.: Highway Trafffic Analysis and Design, Macmillan Education Ltd, Hong Kong (1989) 